\title{
Moraceae endémicas del Perú
}

\section{Pamela Cáceres}

Herbario Forestal. Departamento de Ciencias Forestales, Universidad Nacional Agraria, La Molina, Lima, Perú.

pcbforest@hotmail.com

\section{Resumen}

La familia Moraceae es reconocida en el Perú por presentar 19 géneros y 128 especies (Brako \& Zarucchi, 1993; Ulloa Ulloa et al., 2004), la mayoría arbóreas y/o hemiepífitos. En este trabajo reconocemos dos especies endémicas en igual número de géneros. Las especies endémicas se encuentran en la región Bosques Húmedos Amazónicos, entre los 115 y 220 m de altitud. Ambas especies endémicas se encuentran dentro del Sistema Nacional de Áreas Naturales Protegidas por el Estado.

Palabras claves: Moraceae, Perú, endemismo, plantas endémicas.

\section{Abstract}

The Moraceae are represented in Peru by 19 genera and 128 species (Brako \& Zarucchi, 1993; Ulloa Ulloa et al., 2004), mostly trees and hemiepiphytes. Here we recognize two endemic species, in the same number of genera. These endemic species are found in Humid Lowland Amazonian Forests region, between 115 and 220 m elevation. Both endemic Moraceae have been recorded in within Peru's protected areas system.

Keywords: Moraceae, Peru, endemism, endemic plants.

\section{Naucleopsis velutina C.C. Berg}

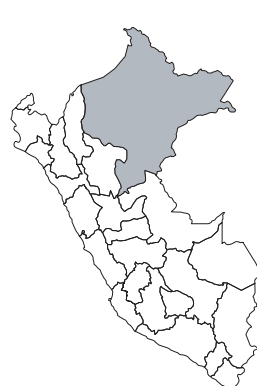

\section{EN, B1a}

Publicación: Novon 6(3): 241. 1996.

Colección tipo: R. Vásquez et al. 14263

Herbarios: MO.

Nombre común: Desconocido.

Registro departamental: LO.

Regiones Ecológicas: BHA; $130-220 \mathrm{~m}$. SINANPE: RNPS

Herbarios peruanos: AMAZ (1).

Observaciones: Árbol dioico, conocido de unas pocas localidades en la Amazonía peruana. El tipo corresponde a una planta masculina recolectado en 1990, en un área próxima a la Reserva Nacional Allpahuayo-Mishana, aunque no incluida por Vásquez (1997) en la flora del área. Existe poco información para esta especie; sin embargo se encuentra dos poblaciones registradas en la Reserva Nacional Pacaya Samiria. Poco se sabe del estatus de otros ambientes propicios para esta especie fuera de áreas protegidas.

\section{Perebea longepedunculata C.C. Berg}

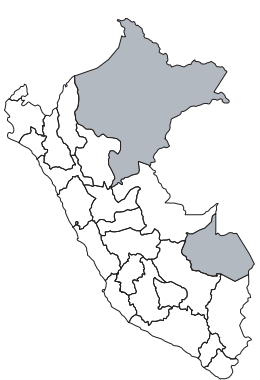

LC

Publicación: Acta Bot. Neerl. 18(3): 463. 1969.

Colección tipo: G. Klug 2563

Herbarios: NY, U.

Nombre común: Desconocido.

Registro departamental: LO, MD.

Regiones Ecológicas: BHA; 115-200 m. SINANPE: RNPS

Herbarios peruanos: Ninguno.

Observaciones: Árbol conocido de por lo menos ocho localidades en la Amazonía peruana. Esta especie ha sido recolectada en bosques estacionalmente inundables. Por lo menos tres poblaciones reciben algún tipo de protección, por estar ubicadas en un área protegida del Estado y en otras privadas. 